\title{
Ovarian Follicular Concentrations of Activin, Follistatin, Inhibin, Insulin-Like Growth Factor I (IGF-I), IGF-II, IGF-Binding Protein-2 (IGFBP-2), IGFBP-3, and Vascular Endothelial Growth Factor in Spontaneous Menstrual Cycles of Normal Women of Advanced Reproductive Age*
}

\author{
NANCY A. KLEIN, DAVID E. BATTAGLIA, TERESA K. WOODRUFF, \\ VASANTHA PADMANABHAN, LINDA C. GIUDICE, WILLIAM J. BREMNER, AND \\ MICHAEL R. SOULES
}

University of Washington (N.A.K., D.E.B., W.J.B., M.R.S.), Seattle, Washington 98105; Northwestern University (T.K.W.), Chicago, Illinois 60208; University of Michigan (V.P.), Ann Arbor, Michigan 48109; and Stanford University (L.C.G.), Stanford, California 94305

\begin{abstract}
Previous studies indicate that the menstrual cycles of older reproductive age women are characterized by a selective elevation of FSH associated with early development and ovulation of a dominant follicle. Several intraovarian hormones and growth factors have been identified that appear to serve important paracrine roles. The purpose of this study was to examine follicular fluid (FF) hormones and growth factors in the dominant follicle of unstimulated cycles of older, ovulatory women. We aspirated FF from the preovulatory dominant follicle in natural menstrual cycles of older subjects (age, 40-45 yr; $\mathrm{n}=$ 20 ) and younger controls (age, 20-25 yr; $\mathrm{n}=19$ ). FF was analyzed for estradiol, progesterone, testosterone, androstenedione, inhibin A and B, total activin A, total follistatin, insulin-like growth factor I (IGF-I),
\end{abstract}

IGF-II, IGF-binding protein-2 (IGFBP-2), IGFBP-3, and vascular endothelial growth factor (VEGF) concentrations. We found that the dominant follicles from older women contain normal concentrations of steroids, inhibin A and B, IGF-II, IGFBP-2, and IGFBP-3; increased concentrations of follistatin, activin $\mathrm{A}$, and VEGF; and decreased concentrations of IGF-I. Therefore, under the influence of elevated $\mathrm{FSH}$, the dominant follicle in older women is highly competent in terms of hormone and growth factor secretion. We postulate that elevated FF activin may be related to the early ovulation observed in older women, whereas elevated VEGF may be related to the meiotic spindle abnormalities observed in the oocytes of older reproductive age women. (J Clin Endocrinol Metab 85: 4520-4525, 2000)
$\mathrm{T}^{\circ}$ CHARACTERIZE early age-related changes in the hypothalamic-pituitary-ovarian axis, we have conducted a series of studies in normal, ovulatory women, aged 40-45 yr. These studies have demonstrated 1) a monotropic rise in FSH throughout the menstrual cycle (1);2) accelerated dominant follicle development and early ovulation, but otherwise normal follicle growth and ovarian steroid secretion $(1,2)$; and 3) disorganization of the oocyte meiotic spindle (3, 4). We were unable to detect any changes in the bioactivity of the FSH molecule (1) or changes in GnRH pulsatility (5). In the current study we continue to characterize the agerelated changes in the hypothalamic-pituitary-ovarian axis through a more detailed analysis of the follicular fluid (FF) contents of hormones and growth factors in the dominant follicle.

Inhibin and activin are glycoprotein dimers produced by

Received January 4, 2000. Revision received April 21, 2000. Rerevision received August 28, 2000. Accepted September 2, 2000.

Address all correspondence and requests for reprints to: Nancy A. Klein, M.D., 4225 Roosevelt Way NE, Suite 305, Seattle, Washington 98105. E-mail: nklein@u.washington.edu.

* This work was supported by NIH Grants R01-HD-18967, R01-HD31915, R01-AG-14579, and M01-RR-00037. granulosa cells that are defined by their ability to suppress (inhibin) $(6,7)$ and stimulate (activin) $(6,8)$ FSH synthesis and secretion. Follistatin is a single chain polypeptide that is also an inhibitor of FSH (6), but primarily functions as a potent binding protein of both activin and inhibin (9). The net effect of these hormones is dependent on the relative amounts present, the amount of bioavailable ligand, and the available receptors. After the development of specific, two-site ELISAs for dimeric inhibin, it was demonstrated that serum inhibin $\mathrm{B}$ was decreased in the early follicular phase of older, ovulatory women with FSH elevation (10-14). Reame and colleagues reported that as well as decreased inhibin B, older ovulatory women had increased circulating levels of total activin A (12). In addition to their endocrine roles as FSH modulators, inhibin and activin appear to have multiple autocrine/paracrine roles in follicle development, including promotion of follicle growth by inhibin (15) and promotion of follicle atresia $(15,16)$, premature ovulation, and oocyte degeneration (16) by activin.

Other putative intraovarian regulators of follicle growth include the GH/insulin-like growth factor (IGF) family of proteins. FF IGF-II levels positively correlate with follicle size and cycle day and inversely correlate with the androgen/ 
estrogen ratio (17). IGFBPs (which primarily inhibit IGF actions by sequestering the peptides) have been identified in human FF in levels that vary with the functional status of the follicles (18). We previously demonstrated that normal older reproductive age women have reduced concentrations of IGF-I (but not IGF-II) in both serum and the FF of the dominant follicle (19). However, binding proteins were not measured in this earlier study, and the significance of this finding is unknown.

Vascular endothelial growth factor (VEGF) is an angiogenic cytokine produced by granulosa cells, and its expression appears to be enhanced in response to hypoxic stimuli (20). Oocytes from follicles with decreased dissolved oxygen FF content demonstrate abnormalities in the organization of chromosomes within the meiotic spindle similar to those observed in older, ovulatory women (21). FF VEGF concentrations may therefore vary in response to age-related differences in ovarian perfusion and intrafollicular oxygen content.

The current study was carried out to further evaluate the roles of dimeric inhibin, activin, follistatin, IGF-I, IGF-II [as well as IGF-binding protein-2 (IGFBP-2) and IGFBP-3], and VEGF in older reproductive age women by determining their relative FF concentrations. We hypothesized that in the older women, the preovulatory dominant follicle contains altered concentrations of one or more of these regulatory hormones. Considering that activin can cause premature ovulation and oocyte degeneration in rodents, we postulated that older ovulatory women would have increased levels of activin in their dominant follicles.

\section{Subjects and Methods}

\section{Subjects}

Normal female volunteers, aged $40-45$ yr (subjects; $\mathrm{n}=20$ ) and $20-25$ yr (controls; $n=19$ ), were recruited for the study. All women were required to have regular ovulatory menstrual cycles [luteal phase progesterone $(\mathrm{P}),>10 \mathrm{nmol} / \mathrm{L}$ ], be healthy with normal body mass index, be taking no medications or exogenous hormones, have no past or current reproductive endocrine problems, participate in no more than $5 \mathrm{~h}$ / week of aerobic exercise, and have normal serum PRL $(<20 \mu \mathrm{g} / \mathrm{L})$ and testosterone $(\mathrm{T} ;<3.5 \mathrm{nmol} / \mathrm{L})$ levels. FF steroid and IGF concentrations have been reported previously for 5 of these subjects (2), and FF inhibin concentrations have been reported for 10 of these subjects (10), who were included in our previous studies. The study protocol was approved by the University of Washington human subjects committee, and written consent was obtained from all volunteers. All participants were provided monetary compensation for their time and inconvenience.

\section{Study procedures}

Dominant follicle development was monitored in a natural menstrual cycle with serial estradiol $\left(\mathrm{E}_{2}\right)$ levels and transvaginal ultrasound. When the dominant follicle measured at least $16 \mathrm{~mm}$ and/or serum $\mathrm{E}_{2}$ was at least $550 \mathrm{pmol} / \mathrm{L}, 10,000 \mathrm{IU}$ hCG were administered im. Thirty-two hours after hCG, transvaginal aspiration of the dominant follicle was performed under ultrasound guidance. FF samples were centrifuged and frozen for subsequent assay. For this study, aliquots of the FF were assayed for dimeric inhibin $\mathrm{A}$ and $\mathrm{B}$, total activin $\mathrm{A}$, total follistatin, IGF-I, IGF-II, IGFBP-2, IGFBP-3, VEGF, $\mathrm{E}_{2}$, androstenedione (A), T, and $P$.

\section{Assays}

FSH. The FSH assay employed was a solid phase two-site fluoroimmunometric (Delfia) assay in which two monoclonal antibodies, supplied by Wallac, Inc. (Gaithersburg, MD), are directed against two separate antigenic determinants on the human gonadotropin molecule. The assay cross-reacts less than $1 \%$ with LH. The intra- and interassay coefficients of variation were $2.3 \%$ and $4.6 \%$, respectively.

$E_{2}$. $E_{2}$ was measured by RIA performed using reagents supplied by ICN Biomedicals, Inc. (Costa Mesa, CA). The antibody cross-reacts $9 \%$ with estrone, $1.5 \%$ with estriol, and less than $1 \%$ with all other steroids. The inter- and intraassay coefficients of variation were $16 \%$ and $7 \%$, respectively.

Inhibin $A$ and $B$. FF levels of inhibin A and inhibin B were measured by enzyme-linked immunosorbent assay (ELISA) as described previously $(22,23)$. Briefly, the assays are two-site ELISAs based on the use of multiwell plates coated with specific monoclonal antibodies to the $\beta_{\mathrm{A}^{-}}$ and $\beta_{\mathrm{B}}$-subunits as capture antibodies. The Fab fraction of a mouse monoclonal antibody to the N-terminal portion of the 20-kDa $\alpha$-subunit (R1) conjugated to alkaline phosphatase is used for detection in both assays. Recombinant inhibin A (National Institute of Biological Standards and Control, Hertfordshire, UK) and inhibin B (Genentech, Inc. South San Francisco, CA) were used as standards. Intra- and interassay coefficients of variation were $8 \%$ and $11 \%$, and the assay detection limit was $7.8 \mathrm{pg} / \mathrm{mL}$ for both assays.

Total activin A. Total activin A was measured using a two-site enzyme immunoassay procedure that incorporates an analyte denaturation and oxidation step (24). Recombinant human activin A (rh-activin A) is used as an assay standard, diluted from frozen aliquots of a $250 \mathrm{ng} / \mathrm{mL}$ stock. Monoclonal antibodies against a synthetic peptide corresponding to residues $82-114$ of the mature $\beta_{\mathrm{A}}$-subunit of human inhibin are covalently coupled to 96-well hydrazide plates (24). Cross-reactivities of less than $0.5 \%$ are observed with inhibin $\mathrm{A}$, inhibin $\mathrm{B}$, and activin $\mathrm{B}$, and cross-reactivities of less than $0.1 \%$ are observed with bovine pro- $\alpha \mathrm{C}$ and follistatin. The assay detection limit is $10 \mathrm{pg} /$ well, and coefficients of variation within and between plates are $4.9 \%$ and $9.1 \%$, respectively.

Follistatin. Total follistatin concentrations were measured using a twosite ELISA (25). The assay uses a pair of mouse monoclonal antibodies generated against follistatin 288 . The assay is specific for follistatin and cross-reacts minimally $(<0.3 \%)$ with inhibin $\mathrm{A}$, inhibin $\mathrm{B}$, activin $\mathrm{A}$, activin $\mathrm{B}$, and activin AB. The cross-reactivity of follistatin-315 in the assay is $9.9 \%$.

FF steroids. Follicular fluid $\mathrm{E}_{2}, \mathrm{P}, \mathrm{T}$, and $\mathrm{A}$ were extracted and separated by Celite chromatography and then measured by RIA as previously described (26).

Western analysis. Qualitative analysis of FF protein complexes was performed as follows. rh-follistatin, rh-activin A (both provided by $\mathrm{Al}$ Parlow, National Hormone and Pituitary Program, Torrance, CA), and rh-inhibin A standards (positive controls) and FF samples were subjected to SDS-PAGE in a $4-20 \%$ or $12 \%$ Tris-glycine gel. Total protein amounts were equivalent per gel lane loaded. Samples were reduced in $10 \%$ SDS sample buffer with $2.5 \% \beta$-mercaptoethanol, then heated at 90 $\mathrm{C}$ for $2 \mathrm{~min}$. The gels were transferred to polyvinylidene difluoride membranes for immunoblot analysis. The monoclonal antibodies used to detect follistatin via immunoblot (Western) analysis were 7FS30 and 6FS6 (provided by Pat Sluss, Massachusetts General Hospital, Boston, $\mathrm{MA}$ ), either alone or in combination, and immunoreactivity was determined using ECL detection (Amersham Pharmacia Biotech, Arlington Heights, IL). The follistatin antibodies detect both the 288- and 315amino acid forms. Inhibin subunits were detected with the $\alpha$ polyclonal chicken antiinhibin antibody, and the $\beta$-subunits were detected with a monoclonal antibody, $6 \mathrm{H} 5$ (provided by Genentech, Inc.). Activin bound to follistatin is not recognized by the $\beta$-subunit antibody, and the complex, once formed, is irreversible (27). All primary antibodies were used at a dilution of 1:2000. The primary antibodies used in the experiment were biotinylated, and incubation of the blot with horseradish peroxidase-strepavidin by itself did not result in the detection of any protein bands (negative control).

IGFs and IGFBPs. IGF-I concentrations were measured using a two-site immunoradiometric assay (IRMA; Active, Diagnostic Systems Laboratories, Inc., Webster, TX). The intra- and interassay coefficients of variation were $7 \%$ and $7.4 \%$, respectively. IGF-II concentrations were mea- 
sured using a two-site IRMA (Active, Diagnostic Systems Laboratories, Inc.) that includes an extraction step to separate the IGF-II from its binding protein. The intra- and interassay coefficients of variation were $6.5 \%$ and $6.3 \%$, respectively. IGFBP-2 concentrations were measured using a RIA (Diagnostic Systems Laboratories, Inc.). The intra- and interassay coefficients of variation were $8.5 \%$ and $7.6 \%$, respectively. IGFBP-3 concentrations were measured using a two-site IRMA (Active, Diagnostic Systems Laboratories, Inc.). The intra- and interassay coefficients of variation were $3.9 \%$ and $1.9 \%$, respectively.

$V E G F$. FF concentrations of VEGF were quantified using a quantitative sandwich enzyme immunoassay that uses a horseradish peroxidaselinked VEGF polyclonal antibody for detection (Quantikine, R\&D Systems, Inc. Minneapolis, MN) with recombinant human VEGF as a standard (21). Optical density readings were obtained at $450 \mathrm{~nm}$ in a microtiter plate reader (TiterTek Multiskan MC, ICN Biomedicals, Inc.). The sensitivity of the assay ranges from $5-9 \mathrm{pg} / \mathrm{mL}$, and the intra- and interassay coefficients of variation are less than $10 \%$.

\section{Statistics}

The mean and SEM for all hormone concentrations were calculated for each age group. Mean values were then compared between groups by Mann-Whitney $U$ test. For each analysis, $P<0.05$ was considered to represent a significant difference.

\section{Results}

Similar to our previously reported results, the older subjects had higher early follicular phase concentrations of FSH and $E_{2}$ and more rapid development of the dominant follicle, meeting criteria for hCG by an average of 4.6 days earlier in the cycle compared with controls (Table 1). Results for FF hormone concentrations (mean \pm SEM) are shown in Figs. 1-3. Not all subjects had sufficient aliquots of FF to perform all assays; therefore, the numbers of subjects represented by each mean value are indicated in the figures.

There were no differences in the FF concentrations of $E_{2}$, A, T, or P between subjects and controls (Fig. 1). As previously reported (2), there was a trend toward higher $E_{2}$ and lower $\mathrm{T}$ concentrations in the older subjects with a higher $\mathrm{E}_{2} / \mathrm{T}$ ratio; however, this did not reach statistical significance (1.0 vs. 0.7; $P=0.09$ ). There were also no differences in FF levels of inhibin A or inhibin B, whereas older subjects had significantly higher FF concentrations of total activin A and total follistatin (Fig. 2).

Western blot analysis revealed that inhibin and follistatin are found in the FF as a complex (Fig. 3). The abundance of the inhibin-follistatin complex did not change between FF samples. Upon reduction, free follistatin of the expected size of $34 \mathrm{kDa}$ was detected, and inhibin was released from a complex and detected at the expected mature size of $32 \mathrm{kDa}$. The detected inhibin did not reduce to $\alpha$ - and $\beta$-subunits under these conditions. No free activin A was detected in any

TABLE 1. Subject characteristics and dominant follicle development

\begin{tabular}{lccc}
\hline & $\begin{array}{c}\text { Subjects } \\
(\mathrm{n}=20)\end{array}$ & $\begin{array}{c}\text { Controls } \\
(\mathrm{n}=19)\end{array}$ & $\begin{array}{c}\mathrm{P} \\
(t \text { test })\end{array}$ \\
\hline Age & $42.0 \pm 0.4$ & $23.5 \pm 0.4$ & $<0.001$ \\
Day 3 FSH $(\mathrm{mIU} / \mathrm{mL})$ & $7.6 \pm 0.7$ & $4.4 \pm 0.3$ & $<0.001$ \\
Day 3 E $\mathrm{F}_{2}(\mathrm{pmol} / \mathrm{L})$ & $302 \pm 44$ & $177 \pm 11$ & 0.013 \\
$\mathrm{E}_{2} @ \mathrm{hCG}(\mathrm{pmol} / \mathrm{L})$ & $932 \pm 81$ & $822 \pm 48$ & $\mathrm{NS}$ \\
Mean follicle diameter at time of & $19.0 \pm 0.5$ & $19.3 \pm 0.5$ & $\mathrm{NS}$ \\
$\quad$ hCG $(\mathrm{mm})$ & $12.0 \pm 0.4$ & $16.6 \pm 0.6$ & $<0.001$ \\
Day of follicle aspiration & & & \\
\hline
\end{tabular}

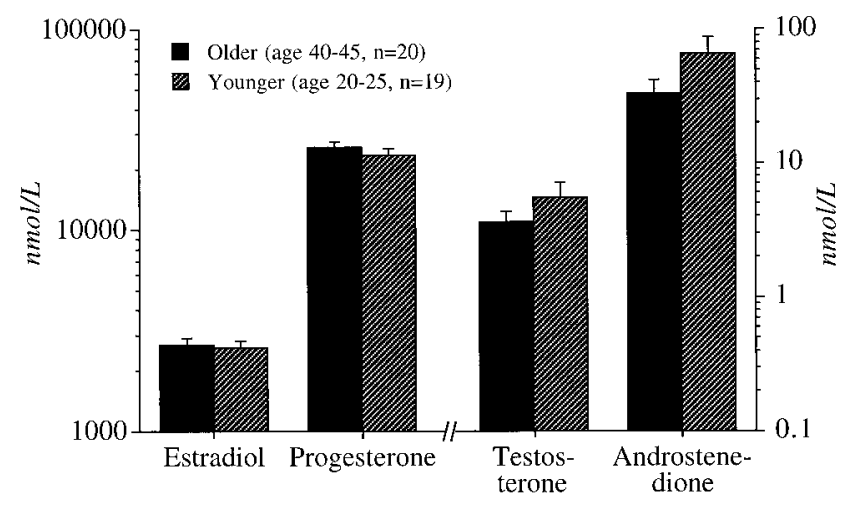

FIG. 1. Mean \pm SEM FF concentrations of $\mathrm{E}_{2}, \mathrm{P}, \mathrm{T}$, and $\mathrm{A}$ for older subjects (age, 40-45 yr) and younger controls (age, 20-25 yr). There were no significant differences in steroid concentrations between the age groups.

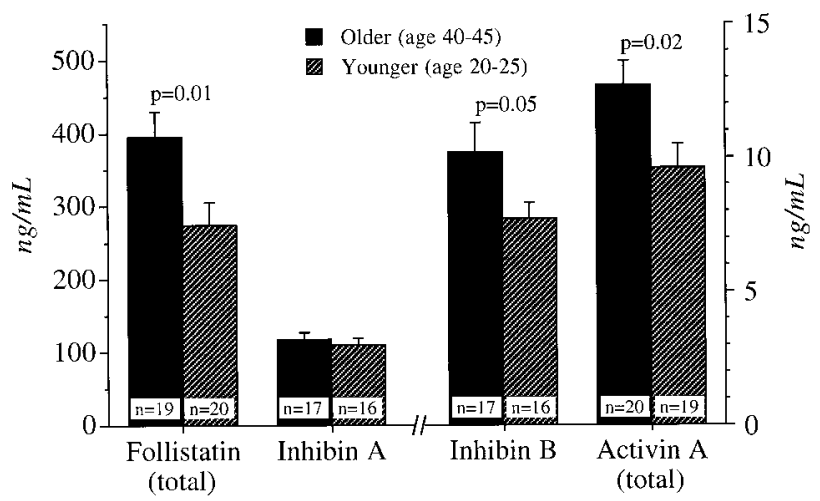

FIG. 2. Mean \pm SEM FF concentrations of total follistatin, total inhibin A and B, and total activin A for older subjects (age, 40-45 yr) and younger controls (age, 20-25 yr). Older subjects had significantly greater concentrations of total follistatin and activin A. There were no significant differences in concentrations of inhibin A or inhibin B between the age groups.

of the samples; therefore, activin A levels were either below the sensitivity of the method or present only in a bound form [once formed, the follistatin-activin complex is irreversible and not recognized by the $\beta$-subunit antibody (27)].

FF levels of IGF-I, IGF-II, IGFBP-2, and IGFBP-3 are shown in Fig. 4. The intrafollicular concentration of IGF-I was lower in the older subjects, and there was a trend toward higher concentrations of IGFBP-2 (which would further decrease the available IGF-I), but the difference did not reach statistical significance $(P=0.18)$. Concentrations of IGF-II and IGFBP-3 were similar in the two age groups.

Older subjects had higher FF concentrations of VEGF compared with younger controls $[2.89 \pm 1.53(\mathrm{n}=20)$ vs. $1.61 \pm$ 0.65 ( $\mathrm{n}=17) ; P=0.02]$.

\section{Discussion}

Substantial evidence exists for a paracrine/autocrine role of activin at the level of the ovarian follicle. $\beta$-Subunit messenger ribonucleic acid without $\alpha$-subunit messenger ribonucleic acid is expressed in small antral follicles in the macaque; therefore, activin may be preferentially secreted by these smaller follicles, whereas inhibin is secreted by the more mature antral (Graffian) follicles (28). Granulosa 

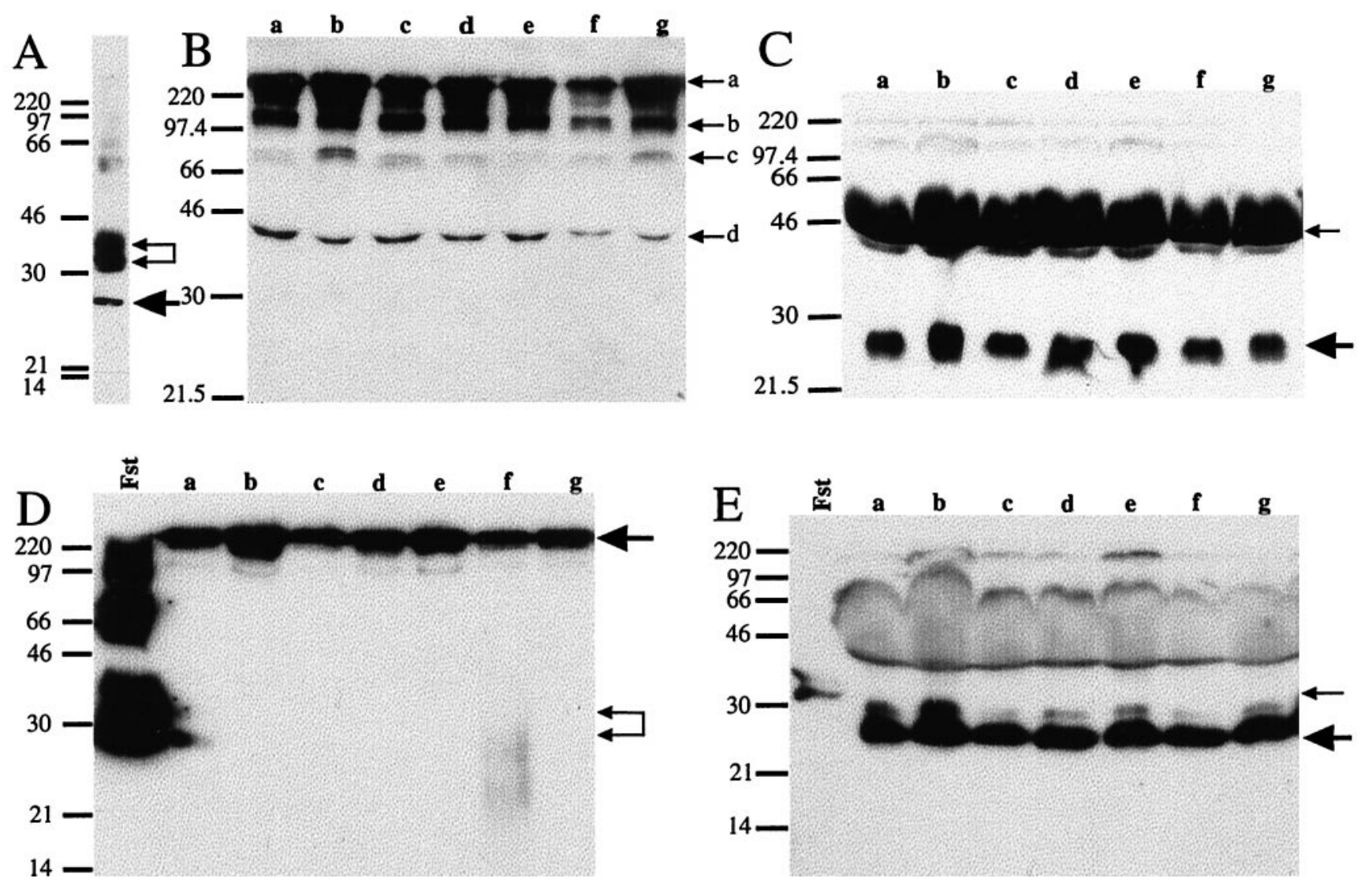

Fig. 3. A, rh-activin A and rh-inhibin A incubated with antiinhibin/activin antibody cocktail. B, Nonreduced follicular fluid samples incubated with antiinhibin/activin antibody cocktail. C, Reduced FF samples incubated with antiinhibin/activin antibody cocktail. D, rh-follistatin and nonreduced FF samples incubated with antifollistatin antibody cocktail. Representative samples are shown. All samples showed similar patterns and intensity.

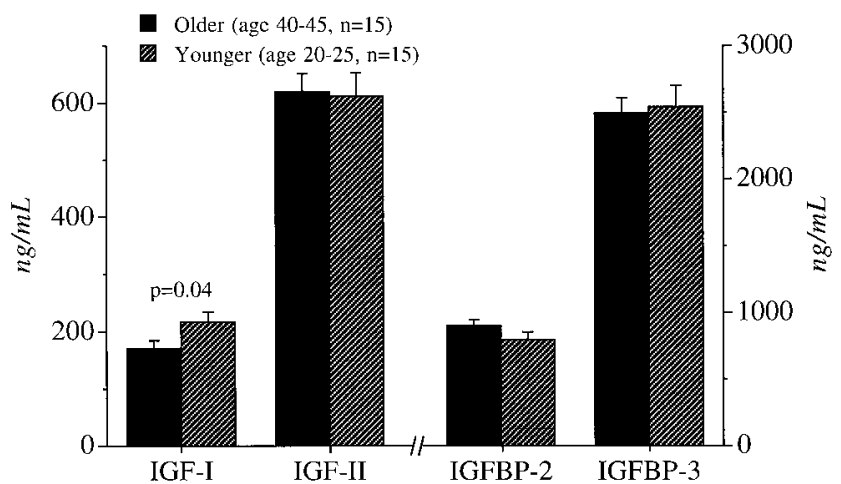

FIG. 4. Mean + SEM FF concentrations of IGF-I, IGF-II, IGFBP-2, and IGFBP-3 in older subjects (age, 40-45 yr) and younger controls (age, 20-25 yr). IGF-I was significantly lower in the older subjects. There were no significant differences in concentrations of IGF-II or either binding protein between the age groups.

cells possess activin receptors (15), and in vitro and in vivo studies in rodent models have demonstrated both stimulatory and inhibitory effects of activin on follicle development and function $(8,15,16,29)$. It is likely that activin has variable effects on the follicle that are dependent on the stage of follicle development and / or other local factors (e.g. relative levels of other intraovarian hormones and growth factors). In the present study we have begun to characterize the potential contributions of activin, follistatin, and the IGF system to the process of reproductive aging by examining their FF concentrations in the preovulatory follicle.

Our findings indicate that both inhibin and activin are present in the FF as a complex with follistatin, and that inhibin is the predominant FF form of the inhibin/activin dimers. There was no evidence of free (bioactive) activin in the FF samples from either our older or younger subjects. Using gel permeation chromatography, previous investigators have reported that the detectable activin A in human FF (eluted with apparent molecular mass $>70 \mathrm{kDa}$ ) is present in a bound form, with little if any free activin A ( $25 \mathrm{kDa})$ present (28). The fact that both total activin A and total follistatin were elevated in the FF of older subjects suggests that elevated follistatin production compensates for the increased FF levels of activin A, thus potentially conferring a protective effect against activin. The fact that the preovulatory dominant follicle does not appear to contain significant levels of free (bioactive) activin does not eliminate the possibility that activin plays an important paracrine role in the early stages of follicle selection and development. In human FF, follistatin is found in levels far exceeding those in serum, and there appears to be a relatively high steady state concentration of follistatin that does not differ among normal dominant, atretic, or small antral follicles (30). This argues against 
changes in follistatin production as a major factor in the regulation of follicle selection and atresia.

IGF-I has been shown to serve as an intraovarian regulator of follicle function in rodents, and it exerts direct effects on human and rodent granulosa cell function $(31,32)$. In vitro, IGF-I, in conjunction with gonadotropins, appears to have a role as a promoter of follicle growth (33) and steroid secretion $(34,35)$ and as an antiatretic hormone (36). In vivo, adjuvant therapy with GH increased sensitivity to exogenous gonadotropins in women undergoing controlled ovarian hyperstimulation associated with elevated FF levels of IGF-I (37). In the current study older subjects had lower FF concentrations of IGF-I and a trend toward higher concentrations of IGFBP-2. Together, these changes would result in a reduced local hormone effect. If there is a decrease in the bioavailable IGFs, this may have some relevance to alterations in oocyte maturation, as it has been shown that IGF-I can accelerate oocyte maturation in vitro (38). The possibility that activin A action could be mediated in part through the IGF system is supported by the finding that activin A promoted IGFBP production by cultured human granulosa cells (39).

The finding of elevated VEGF in the FF of older subjects is interesting, given that VEGF production may be enhanced in response to hypoxic stimuli (20). Van Blerkom and Coworkers demonstrated that oocytes from follicles with reduced FF oxygen content after controlled ovarian hyperstimulation have an increased rate of abnormalities of the meiotic spindle in the metaphase II oocyte (21). Whether there is a relationship between ovarian perfusion, intrafollicular oxygen content, VEGF secretion, and the meiotic spindle abnormalities observed in older women deserves further study.

To assure uniform exposure among subjects to a luteinizing stimulus (as well as to make follicle aspiration and oocyte retrieval logistically possible), it was necessary to administer exogenous hCG before follicle aspiration. In a prior study using separate groups of normal women selected in the same manner, we noted that the groups demonstrated no differences in follicle size or peak $\mathrm{E}_{2}$ levels at the time of the spontaneous LH surge (1). Although the dose, criteria for administration, and duration of exposure were uniform among subjects, the possibility that differential responses to exogenous hCG could either obscure or exaggerate physiological differences between groups cannot be entirely excluded.

In conclusion, the dominant follicle in older reproductive age women with FSH elevation appears to be compensated in terms of hormone secretion despite accelerated follicular development. This supports the concept that early follicular phase inhibin B deficiency reflects decreased numbers of antral follicles rather than reduced granulosa cell secretory capacity. One could speculate that similar to the premature ovulation and follicle atresia induced experimentally by exogenous activin in the rat (16), an enhanced paracrine effect of activin A may promote the accelerated follicle development, follicle depletion, early ovulation, and oocyte abnormalities observed in older women. Further studies are needed to clarify the roles of activin and inhibin dimers and the IGF hormones in aging of the female reproductive system, particularly in the early stages of follicle selection and development.

\section{Acknowledgments}

We acknowledge Ms. Gretchen Davis for her invaluable assistance with subject recruitment and study coordination, Dr. Bill Hopper for performing the FF steroid assays, and Dr. John Van Blerkom for performing the VEGF assays. We also thank Drs. Lee Evans and Nigel Groome for their valuable assistance with the Follistim and inhibin assays. We especially appreciate the women who volunteered to participate in our study

\section{References}

1. Klein N, Battaglia D, Fujimoto V, Davis G, Bremner W, Soules M. 1996 Reproductive aging: accelerated follicular development associated with a monotropic follicle stimulating hormone rise in normal older women. J Clin Endocrinol Metab. 81:1038-1045.

2. Klein N, Battaglia D, Miller P, Brannigan E, Guidice L, Soules M. 1996 Ovarian follicular development and the follicular fluid hormones and growth factors in normal women of advanced reproductive age. J Clin Endocrinol Metab. 81:1946-1951.

3. Battaglia D, Goodwin P, Klein N, Soules M. 1996 Influence of maternal age on meiotic spindle assembly in oocytes from naturally cycling women. Hum Reprod. 11:2217-2222.

4. Battaglia D, Klein N, Soules M. 1997 Changes in centrosomal domains during meiotic maturation in the human oocyte. Mol Hum Reprod. 2:845-851.

5. Klein N, Battaglia D, Clifton D, Bremner W, Soules M. 1996 The gonadotropin secretion pattern in normal women of advanced reproductive age in relation to the monotropic FSH rise. J Soc Gynecol Invest. 3:27-32.

6. Carroll R, Corrigan A, Gharib S, Vale W, Chin W. 1989 Inhibin, activin and follistatin: regulation of follicle-stimulating hormone messenger ribonucleic acid levels. Mol Endocrinol. 3:1969-1989.

7. Rivier C, Schwall R, Mason A, Burton L, Vaughan J, Vale W. 1991 Effect of recombinant inhibin on luteinizing hormone and follicle-stimulating hormone secretion in the rat. Endocrinology. 128:1548-1554.

8. Stouffer R, Woodruff T, Dahl K, Hess D, Mather J, Molskness T. 1993 Human recombinant activin-A alters pituitary luteinizing hormone and follicle-stimulating hormone secretion, follicular development, and steroidogenesis during the menstrual cycle in rhesus monkeys. J Clin Endocrinol Metab. 77:241-248.

9. Krummen L, Woodruff T, de Guzman G, et al. 1993 Identification and characterization of binding proteins for inhibin and activin in human serum and follicular fluids. Endocrinology. 132:431-443.

10. Klein N, Illingworth P, Groome M, McNeilly A, Battaglia D, Soules M. 1996 Decreased inhibin B secretion is associated with the monotropic FSH rise in older, ovulatory women: a study of serum and follicular fluid levels of dimeric inhibin A and B in spontaneous menstrual cycles. J Clin Endocrinol Metab. 81:2742-2745

11. Burger H, Cahir N, Robertson D, et al. 1998 Serum inhibins A and B fall differentially as FSH rises in perimenopausal women. Clin Endocrinol (Oxf). 48:809-813

12. Reame N, Wyman T, Phillips D, de Kretser D, Padmanabhan V. 1998 Net increase in stimulatory input resulting from a decrease in inhibin B and an increase in activin A may contribute in part to the rise in follicular phase follicle-stimulating hormone of aging cycling women. J Clin Endocrinol Metab. 83:3302-3307.

13. Welt C, McNicholl D, Taylor A, Hall J. 1999 Female reproductive aging is marked by decreased secretion of dimeric inhibin. J Clin Endocrinol Metab. 84:105-111.

14. Santoro N, Adel T, Skurnick H. 1999 Decreased inhibin tone and increased activin A secretion characterize reproductive aging in women. Fertil Steril. $71: 658-662$

15. Woodruff T, Lyon R, Hansen S, Rice G, Mather J. 1990 Inhibin and activin locally regulate rat ovarian folliculogenesis. Endocrinology. 127:1237-1242.

16. Erickson G, Kokka S, Rivier C. 1995 Activin causes premature superovulation. Endocrinology. 136:4804-4813.

17. Van Dessel H, Faessen G, Yap O, Chandrasekher Y, Fauser B, Giudice L. 1996 Serum and follicular fluid levels of insulin-like growth factor (IGF)-I, IGF-II, and IGF binding proteins- 1 and -3 during the normal menstrual cycle. J Clin Endocrinol Metab. 81:1224-1231.

18. Cataldo N, Giudice L. 1992 Insulin-like growth factor binding protein profiles in human ovarian follicular fluid correlate with follicular functional status. J Clin Endocrinol Metab. 74:821-829.

19. Klein N, Battaglia D, Miller P, Soules M. 1996 Circulating levels of growth hormone, IGF-I, and growth hormone binding protein in normal women of advanced reproductive age. Clin Endocrinol (Oxf). 44:285-292.

20. Neeman M, Abramovitch R, Schiffenbauer Y, Tempel C. 1997 Regulation of 
angiogenesis by hypoxic stress: from solid tumours to the ovarian follicle. Int J Exp Pathol. 78:57-70.

21. Van Blerkom J, Schrader R, Antczak M. 1997 The developmental potential of the human oocyte is related to the dissolved oxygen content of follicular fluid: association with vascular endothelial growth factor levels and perifollicular blood flow characteristics. Hum Reprod. 12:1047-1055.

22. Groome N, Illingworth $\mathbf{P}, \mathbf{O}^{\prime}$ Brien $\mathbf{M}$, et al. 1994 Detection of dimeric inhibin throughout the human menstrual cycle by two-site enzyme immunoassay. Clin Endocrinol (Oxf). 40:717-723.

23. Groome N, Illingworth P, O'Brien M, Pai R, Mather J, McNeilly A. 1996 Measurement of dimeric inhibin B throughout the human menstrual cycle. J Clin Endocrinol Metab. 81:1401-1405.

24. Knight P, Muttukrishna S, Groome N. 1996 Development and application of a two-site enzyme immunoassay for the determination of 'total' activin-A concentrations in serum and follicular fluid. J Endocrinol. 148:267-279.

25. Evans L, Muttukrishna S, Groome N. 1998 Development, validation, and application of an ultra-sensitive two-site enzyme assay for human follistatin. J Endocrinol. 156:275-282.

26. Anderson D, Hopper B, Lasley B, Yen S. 1976 A simple method for the assay of eight steroids in small volumes of plasma. Steroids. 28:179-196.

27. Schneyer AL, Rzucidlo DA, Sluss PM, Crowley Jr WF. 1994 Characterization of unique binding kinetics of follistatin and activin or inhibin in serum. Endocrinology. 135:667-674.

28. Schwall R, Mason A, Wilcox J, Bassett S, Zeleznik A. 1990 Localization of inhibin/activin subunit mRNAs within the primate ovary. Mol Endocrinol. 4:75-79.

29. Li R, Phillips D, Mather J. 1995 Activin promotes ovarian follicle development in vitro. Endocrinology. 136:849-856.

30. Erickson G, Chung D, Sit A, DePaolo L, Shimasaki S, Ling N. 1995 Follistatin concentrations in follicular fluid of normal and polycystic ovaries. Hum Reprod. 10:2120-2124.
31. Mason H, Martikamen H, Beard R, Anyaoku V, Franks S. 1990 Direct gonadotrophic effect of growth hormone on oestradiol production by human granulosa cells in vitro. J Endocrinol. 126:1-4.

32. Mason H, Margara R, Winston R, Seppala M, Koistment R, Franks S. 1993 Insulin-like growth factor-I (IGF-I) inhibits production of IGF-binding protein-1 while stimulating estradiol secretion in granulosa cells from normal and polycystic human ovaries. J Clin Endocrinol Metab. 76: 1275-1279.

33. Di Blasio A, Vigano P, Ferrari A. 1994 Insulin-like growth factor-II stimulates human granulosa-luteal cell proliferation in vitro. Fertil Steril. 61:483-487.

34. Christman G, Randolph J, Peegel H, Menon K. 1991 Differential responsiveness of luteinized human granulosa cells to gonadotropins and insulinlike growth factor I for induction of aromatase activity. Fertil Steril. 55:1099-1105.

35. Yong E, Baird D, Yates R, Reichert L, Hillier S. 1992 Hormonal regulation of the growth and steroidogenic function of human granulosa cells. J Clin Endocrinol Metab. 74:842-849.

36. Chun S, Eisenhauer K, Minami S, Billig H, Perlas E, Hsueh A. 1996 Hormonal regulation of apoptosis in early antral follicles: follicle-stimulating hormone as a major survival factor. Endocrinology. 137:1447-1456.

37. Owen E, Shoham Z, Mason B, Ostergaard H, Jacobs H. 1991 Cotreatment with growth hormone, after pituitary suppression, for ovarian stimulation in in vitro fertilization: a randomized, double-blind, placebo-control trial. Fertil Steril. 56:1104-1110.

38. Gomez E, Tarin J, Pelicer M. 1993 Oocyte maturation in humans: role of gonadotropins and growth factors. Fertil Steril. 60:40-46.

39. Cataldo N, Fujimoto V, Jaffe R. 1998 Interferon- $\gamma$ and activin A promote insulin-like growth factor-binding protein- 2 and -4 accumulation by human luteinizing granulosa cells, and interferon- $\gamma$ promotes their apoptosis. J Clin Endocrinol Metab. 83:179-186.

\section{American Physiological Society Conference}

Topic: "Genome \& Hormones: An Integrative Approach to Gender Differences in Physiology"

Date: October 18-20, 2001

Location: Pittsburgh, Pennsylvania

Abstracts Deadline: June 1, 2001

Advance Registration Deadline: August 3, 2001

For more information, or to receive a Call for Papers, contact the APS Membership Department, 9650 Rockville Pike, Bethesda, Maryland 20814-3991. Call 301-530-7171; Fax: 301-571-8313; E-mail: meetings@aps.faseb.org; Web: www.the-aps.org. 